\title{
Encontrando el lugar. Identidad geográfica en los cómics de Roberto Fontanarrosa
}

\author{
Finding the place. Geographical \\ identity in Roberto Fontanarrosa's comics \\ Patricia Ayala García
}

Universidad de Colima (México)

Patricia Ayala García es profesora investigadora de tiempo completo en el Instituto Universitario de Bellas Artes de la Universidad de Colima (Colima, México). Estudió dos maestrías y un doctorado en la Universidad de Columbia de Nueva York. Merecedora de las becas Fulbright, FECA, FONCA, INBA, PADID y SEP para estudios en el extranjero. Cuenta con cuatro libros editados, ha publicado en revistas indexadas de México, Chile y España. Ha participado en veintiuna exposiciones colectivas de fotografía, pintura y escultura en México y Estados Unidos. Actualmente es directora de la Sociedad de Narradores Gráficos de Colima ( $\mathrm{SoNaGraCo}$ ) y realiza investigaciones sobre caricatura e historietica, temas que ha trabajado y divulgado desde 2005. Ha presentado ponencias en encuentros internacionales en Nueva York, Estocolmo y Ámsterdam. En 2016 fue ponente invitada en la Comic-Con Internacional de San Diego.

Fecha de recepción: 5 de marzo de 2018

Fecha de aceptación definitiva: 19 de mayo de 2018 


\title{
Resumen
}

El presente texto hace un análisis de las características que Roberto Fontanarrosa creó para otorgar una identidad geográfica a sus personajes. Para explicar la identidad geográfica en la narrativa gráfica, se analiza no solo lo que se plasma en el físico de los personajes, o en el paisaje que los rodea, sino en las historias, reacciones y acciones de los protagonistas. Los elementos que Fontanrrosa usó para crear la identidad geográfica de sus personajes son muy variados: nombres propios, fondos o background de cada historia, uso de onomatopeyas, canciones, estereotipos, letreros y vestuarios entre otros. Fontanarrosa además retrata las profesiones y actividades de sus personajes, que también los identifican propios de algún lugar.

Palabras clave: Identidad geográfica, narrativa gráfica, Roberto Fontanarrosa, Boggie el aceitoso, Inodoro Pereyra.

\begin{abstract}
The present text makes an analysis of the characteristics that Roberto Fontanarrosa created to grant a geographic identity to his characters. To explain geographic identity in graphic narrative, we analyze not only what is captured in the physicality of the characters, or in the landscape that surrounds them, but in the stories, reactions and actions of the protagonists. The elements that Fontanrrosa used to create the geographical identity of his characters are very varied: Names, backgrounds of each story, use of onomatopoeias, songs, stereotypes, signs and costumes among others. Fontanarrosa also portrays the professions and activities of his characters, which help point to their location of origen to them.
\end{abstract}

Keywords: Geographical identity, graphic narrative, Roberto Fontanarrosa, Boggie el aceitoso, Inodoro Pereyra.

\section{Cita bibliográfica}

Ayala García, P. «Encontrando el lugar. Identidad geográfica en los cómics de Roberto Fontanarrosa», en CuCo, Cuadernos de cómic n. ${ }^{\circ} 10$ (2018), pp. 28-45. 
Hay personas que son un lugar, no una persona (Vargas, El negro Fontanarrosa, p. 162).

\section{Introducción}

Un creador de cómics tiene solo un instante para atraer la atención de su lector y situarlo en el tiempo y lugar determinado en el que ocurre la historia. Para descubrir el lugar donde sucede la acción dentro de una historieta no solo se consideran las características físicas de los personajes o el paisaje que los circunda, sino también el comportamiento, las expresiones populares, las reacciones y acciones de los protagonistas retratados en la misma, además de múltiples referencias sociales y los estereotipos de cada cultura. En definitiva, los elementos que se perciben para ubicar la historia crean la identidad geográfica de los personajes. Estos elementos son muy variados y van desde nombres propios o letreros hasta la representación del clima de la localidad que envuelve al protagonista.

Los cómics son una ventana para conocer el imaginario del autor y el mundo que rodea a los personajes. Esta información se forja de sus experiencias, perspectivas y contexto y dan una locación a quien la comunica. Frecuentemente, es necesario que los lectores sepan qué mundo visitan y, en ocasiones, asimilen el lugar como un aspecto primordial para vivenciar la lectura de una historieta. Jason Dittmer, en Comic Book Visualities, señala que la teorización del espacio, el tiempo y la localidad en los cómics es una asignatura joven, que recientemente hace su entrada a las grandes ligas del análisis exclusivo de cómics. ${ }^{1}$

Cada artista utiliza de diferente manera los elementos de identidad geográfica para crear su propio estilo. El presente trabajo abordará el retrato constante y minucioso de la identidad geográfica en las historietas de Roberto Fontanarrosa, excelente exponente de las variadas formas que dan locación a los personajes y que sirven como ejemplo para academizar el análisis de las mismas.

La identidad geográfica que Fontanarrosa otorga en sus obras a sus personajes, constantemente muestra la necesidad de plasmar — de manera muy concreta - lo propio, lo local, lo ajeno, lo conocido y lo fantástico del pasado literario del creador que hoy nos ocupa. Como ejemplos principales, se comentarán tres de sus series de historietas: Inodoro Pereyra, Los clásicos según Fontanarrosa y Boogie el aceitoso, creadas a principios de la década de los años setenta y reeditadas continuamente hasta nuestros días.

${ }^{1}$ Dittmer, J. «Comic book visualities: a methodological manifesto on geography, montage and narration», en Transactions of the Institute of British Geographers New Series, vol. 35, n. 2 (2010), pp. 222-236. 
La importancia de Fontanarrosa en la historia del cómic como creador de identidad geográfica es sustancial, debido a que en sus ejemplos identificamos el grueso de los elementos y características imperiosos para que la historia transmita la cercanía de sus protagonistas con su entorno. Por otro lado, Phil Emerson, en «Doing Comic Geographies», menciona que el estudio de la identidad geográfica puede convertirse en una lectura crítica o en una metodología que nos ayude a entender por qué razón un creador selecciona un espacio geográfico determinado. ${ }^{2}$

\section{Definición de identidad geográfica}

Stephanie Taylor asegura en Narratives of Identity and Place que, recientemente, la identidad geográfica ha cobrado importancia debido a que la tecnología y la globalización permiten experimentar, rápida e inmediatamente, muchos lugares de manera virtual (simulada) o sincretizada. Esto acarrea sentimientos de ansiedad en el espectador y, como consecuencia, deja una sensación de vacío y lejanía por lo propio o un dejo de desdén por la realidad cotidiana y circundante. ${ }^{3}$ Deseamos un lugar reconocible, quizá una zona de confort. Buscamos una sensación casi filosófica de pertenencia geográfica. ${ }^{4}$

Entre las disciplinas artísticas que regularmente presentan una identidad geográfica, tenemos el teatro, la danza, la literatura, el cine, la pintura y la narrativa gráfica o cómic. De tal modo que La Tragedia de Romeo y Julieta de William Shakespeare, la novela El perfume de Patrick Süskind, y la obra pictórica de Jacques-Louis David: Marat, nos muestran una Verona, un París y un cuarto de baño, esenciales para darle un ambiente específico a la obra, y difieren sobre manera de obras como Esperando a Godot de Samuel Beckett, la película El planeta salvaje y la pintura El beso de Francesco Hayez por sus representaciones manifiestas del lugar donde ocurre la acción. Mientras que las primeras determinan con detalle su ubicación geográfica, las segundas dejan a la imaginación de la audiencia sus locaciones. Evidentemente, es decisión del autor de la obra el peso que le da al lugar donde ocurre la historia. En este sentido, coincidimos con Jason Dittmer al señalar que las posibilidades narrativas del cómic invitan al lector a imaginar el tiempo y el espacio en formas únicas, específicas del cómic, por lo tanto, el inicio de la obra mostrará claramente qué espera el lector de la misma, y cuál será el peso o importancia de su geografía y temporalidad en relación con la historia. ${ }^{5}$

El análisis de la obra creativa incluye enfoques necesarios para explicar la relación directa entre el espacio donde se desarrolla la acción y las temáticas de la obra. En cuanto a los estudios sobre narrativa gráfica, es reciente el uso de teorías para explicar los lugares donde

2 Emmerson, P. «Doing comic geographies», en Cultural Geographies, vol. 23, n. o 4, (2016), pp. 721-725.

3 TAYlor, S. Narratives of Identity and Place. London, Routledge, 2010, p. 45.

${ }^{4}$ Martín-Barbero, J. «Jóvenes: comunicación e identidad», en Revista Pensar Iberoamérica (0), OEI, (2002), pp. 1-15.

${ }^{5}$ Dittmer, J. Op. cit. 
ocurre la acción. ${ }^{6}$ Es acertado que a este conjunto de elementos que establecen la locación, ambiente o atmósfera de una historia se le llame identidad geográfica siempre y cuando podamos hablar de que tal cosa existe y es perceptible por el espectador. Según Agustín Hernando, al adentrarse en un cómic, o en una narración artística, el lector recrea de manera imaginaria el lugar, con la información que le proporciona el artista. ${ }^{7}$

Para Phil Emerson, la narrativa gráfica es un modo de pensamiento en donde estos procesos de comunicación entre el emisor y el receptor son posibles ya que desde la primera viñeta se crea una relación de confianza entre ambos. ${ }^{8}$ Muchos autores de historietas se apoyan en una descripción minuciosa de la geografía física y cultural de sus personajes para crear una historia que transmita a los lectores un sentido de pertenencia a un lugar determinado. La construcción de la identidad geográfica crea parte de un mundo maravilloso al que se adentra un lector de cómics cuando inicia su lectura. Esta geografía, estos lugares, aunque tengan referentes directos aun calcadas de localidades existentes en la vida real, se consideran una construcción subjetiva, del imaginario del creador.

Mercedes Rodríguez Pequeño en «Crónica urbana e identidad geográfica...» opina que «[e]1 lugar repercute en los personajes, y sirve para interpretar el mundo, la ideología, la sociedad y la propia identidad [en el arte] [...] lo que ocurre depende estrechamente de dónde ocurre». ${ }^{9}$ Retomando los postulados de Rebeca Pérez Arriaga, la identidad geográfica en expresiones creativas - que implican una narrativa- pueden definirse como los espacios concretos asociados a la experiencia particular, las sensaciones y valores de los individuos, a su relación personal con el entorno, a la percepción que tiene de él según sus condiciones culturales y personales. El lugar entendido como espacio de la vivencia directa, de la experiencia como complejo de sensaciones, emociones, concepciones y pensamiento. ${ }^{10}$

El lugar donde se nace y se crece determina, en cierto modo, nuestra forma de concebir el mundo, de estar en él. Para Daniel Ausente, en los cómics, «la ecuación geográfica se resuelve por sentido común ${ }^{11}$ porque cuando se lee una historieta, la identidad geográfica refleja el sentimiento de cercanía, de reconocimiento e incluso de extrañeza que un individuo siente por el lugar donde se encuentra.

${ }^{6}$ Ibid., p. 226.

${ }^{7}$ Hernando, A. «Retórica iconográfica e imaginación geográfica: los frontispicios de los atlas como proclamaciones ideológicas», en Boletín de la A. G.E., n. ${ }^{0}$ 51, (2009), pp. 353-369.

8 Emmerson, P. Op. cit., p. 723.

9 Rodríguez Pequeño, M. «Crónica urbana e identidad geográfica en la narrativa de Miguel Delibes y Francisco Umbral», en Actas XLV, AEOE, (s.f.), p. 331.

10 Pérez Arriaga, R. «La ciudad, lugar de identidad geográfica y cultural», en Fermentum. Revista Venezolana de Sociología y Antropología, vol. 19, n. ${ }^{\circ}$ 54, (2009), pp. 35-47, p. 45.

11 Ausente, D. «La memoria gráfica y las sombras del pasado», en García, S. (coord.). Supercómic. Mutaciones de la novela gráfica contemporánea. Madrid, Errata naturae, 2013, p.109. 
Esta sensación puede ser experimentada por una persona o por un colectivo y el lugar representado puede ser un barrio, un vecindario, un pueblo, una ciudad, un país, un continente, un planeta o una galaxia, «invitando al lector a reconocer y desentrañar las numerosas claves que encierra su exuberante y meticulosa iconografía». ${ }^{12} \mathrm{Al}$ tiempo que presenta — de acuerdo con Emerson - una agenda política o de crítica social, debido a que el cómic es un medio práctico reflexivo y cada uno de sus elementos, decididos por el creador, tienen también un fin concreto. $^{13}$

Para conocer por qué la identidad geográfica es importante en el cómic, se podría especular que estar con gente que tiene un lugar geográfico es una sensación muy agradable de pertenencia compartida. En ocasiones, los cómics hacen sentir a la gente como en casa cuando presentan una atmósfera placentera o reconocible. El lector puede conectarse con el lugar donde ocurre la acción a través de los personajes e identificarse con la sensación o emoción que les produce su entorno. Cuando lee un cómic, el lector se siente amparado porque percibe que está entrando a un mundo de fantasía creado específicamente para él. ${ }^{14}$

\section{Primeras imágenes: inicios de la identidad geográfica visual}

Desde mediados del siglo XVI, algunas imprentas europeas comenzaron a publicar libros de mapas llamados «atlas del mundo» y decoraban sus frontispicios, o primeras páginas, con imágenes de nativos de diferentes locaciones geográficas, haciendo conscientes a los lectores de las conexiones de los rasgos físicos de cada nativo con su lugar de origen. Así, por ejemplo, culturalmente se aceptó representar a los africanos como negros semidesnudos con huesos y plantas decorando sus cabezas, se personificó a Europa como una dama completamente vestida, mientras las nativas de América eran mujeres en taparrabo con los senos al aire y las cabezas decoradas con plumas. Se personalizó a los orientales de color amarillo con ropas holgadas y largas trenzas. Los nativos sudamericanos se caracterizaron rebeldes y caníbales. Los habitantes de países árabes vestían ropas elaboradas y turbantes. ${ }^{15}$

Todas y cada una de estas representaciones pueden encontrarse en las historietas europeas del siglo xix y de principios del siglo xx. El cómic belga Tintín, ya desde 1929, usó muchas de estas representaciones que por los últimos cien años se han conservado como elementos de la creación de la geografía en muchos cómics. Después de varios siglos repitiendo esquemas físicos y culturales de los atlas, aún hoy se utilizan los estereotipos

12 Hernando, A. «Retórica iconográfica e imaginación geográfica: los frontispicios de los atlas como proclamaciones ideológicas», en Boletín de la A.G.E., n. ${ }^{\circ}$ 51, (2009), pp. 353-369, pp. 358-359.

13 Emmerson, P. Op. cit., p. 724.

14 Ayala, P. El cómic y sus razones. México, Universidad de Colima, 2016, p. 85.

15 Hernando, A. Op. cit., p. 354. 
como el elemento más común para definir la identidad geográfica de un personaje y las características físicas son comúnmente la primera pista para descubrir dónde vive un personaje. ${ }^{16}$

Aunque, en el pasado, los autores de cómics se basaron en estereotipos para ubicar geográficamente a sus protagonistas, actualmente la mayoría de los caricaturistas tratan de evitar los estereotipos y de establecer la identidad de cada protagonista de la manera más creativa posible. Así lo hizo Hergé, creador de Tintín, que asimiló que los estereotipos no eran la única manera de indicar procedencia geográfica, y trabajó minuciosamente para representar vivencias cotidianas de algunas de las culturas que retrató. ${ }^{17}$ Es claro que los estereotipos pueden ayudar a crear la atmósfera, escenografía y fondo de una historieta, pero existen otros elementos que también ayudan a lograrlo a través de la descripción visual y verbal de las características reconocibles de los lugares dentro del cómic.

Además de las características físicas ya mencionadas, en la historia del cómic, los estereotipos geográficos se mezclaron muchas veces de manera errónea con características culturales y sociales de sus comunidades: tal es el caso de la antropofagia o canibalismo, la higiene, el estado salvaje o incivilizado de los pueblos y hasta rasgos de maldad si dichos grupos no compartían el ideal moral eurocéntrico.

En los orígenes del cómic, mientras en Europa y Norteamérica se utilizaban los estereotipos para dar procedencia a los personajes, en Latinoamérica, incluyendo México, no solo se utilizaban los estereotipos propios de cada región geográfica basados en ilustraciones de atlas, sino, además, aquellos basados en la clase social, profesiones y poblaciones marginadas y, por ende, no faltaban el rico con su puro y su lente de un solo ojo, el descalzo pobre con su mula y los indígenas o nativos de regiones apartadas de las grandes ciudades, con sus vestimentas típicas. De esta manera, un cómic se transforma en un mapa temporal, un mapa del tiempo y el espacio de una historia. ${ }^{18}$

\section{Génesis de las historias: Fontanarrosa y sus lugares}

Nacido en 1944 en la ciudad de Rosario, Argentina, Fontanarrosa es considerado, hoy en día, uno de los más grandes historietistas del mundo. Durante casi cincuenta años, sus cómics se han editado continuamente en volúmenes y antologías. Su arte se considera universal y atemporal: jóvenes y adultos lo leen y lo disfrutan hoy como en el pasado. En vida fue reconocido con varios premios y fue invitado a varios países a compartir sus experiencias. A pesar de su fama, y con la tradición que tienen los creadores de mudarse a las grandes ciudades capitales, Fontanarrosa nunca abandonó Rosario, ciudad en la que decidió permanecer

${ }^{16}$ Dunnetr, O. «Identity and geopolitics in Hergé’s Adventures of Tintin», en Social E̊ Cultural Geography, vol. 10, n. ${ }^{\circ}$ 5, (2009), pp. 583-598.

17 Ibid., p. 594.

18 Dittmer, J. Op. cit., p. 232. 
toda su vida. ${ }^{19}$ Horacio Vargas en El negro Fontanarrosa (2014), argumenta que se quedó en la ciudad debido a su pasión futbolística por el equipo local, y porque sus amistades, familia y su entorno eran muy importantes para él. «No hubo un momento en que decidió quedarse en Rosario por la sencilla razón de que siempre le pareció natural estar en el lugar donde estaba». ${ }^{20} \mathrm{Ni}$ en los momentos de mayor fama en que tuvo que viajar frecuentemente, Fontanarrosa dejó su tierra natal por largos periodos. El apego por su tierra, por lo local y lo formativo de su infancia puede percibirse en una de sus series de historieta más extensas y trascendentes: Inodoro Pereyra. Esta historieta basada en la cultura profunda de su país es la única que siguió creando, aún durante su etapa de enfermad más crítica-cuando dictaba sus trabajos y Óscar Salas los ilustraba. ${ }^{21}$

En la década de los setenta, el mismo autor refiere que Fontanarrosa creó una serie de historietas basadas en historias clásicas de la literatura universal, que posteriormente se agruparon en un libro que lleva por nombre Los clásicos según Fontanarrosa (1980). A la par, Fontanarrosa, también le dio al mundo la historia de Boogie el aceitoso. Es a través de esta serie y de su protagonista que muchos lectores foráneos se han adentrado en otros trabajos más locales del autor, tales como la serie de Inodoro Pereyra y su larga colección de historietas. A diferencia del retrato de lo propio y lo local que Fontanarrosa plasmó en Inodoro, Los clásicos y Boogie están situados en mundos lejanos en tiempo y en distancia que Fontanarrosa conoció a través de la literatura, el cine, la cultura popular o alguna visita turística y que hoy en día puede verse como una crítica política del sistema. ${ }^{22}$

Los cómics de Fontanarrosa poseen numerosos elementos que crean la identidad geográfica de sus personajes con un abanico muy variado y pautas muy específicas. Aunque Fontanarrosa creó estas series de manera sincrónica, los tres ejemplos presentan diferencias en la construcción de lugares para persuadir al lector de que la acción ocurre ahí. Las series de historietas Inodoro Pereyra, Los clásicos según Fontanarrosa y Boogie el aceitoso son prueba fehaciente de que el universo creativo de Fontanarrosa incluía sus intereses y necesidades de plasmar lo que le rodeaba, los mundos conocidos, añorados, imágenes de cine, políticas dolorosas y los mundos fantásticos de la cultura lectora que lo marcó. Si bien el estilo y la forma de estas series variaron con el paso de los años, los elementos básicos de cada historieta mantuvieron su temática, tamaño de publicación e identidad geográfica durante toda su producción.

\section{Fontanarrosa: creador de mundos fantásticos}

Tres son las categorías en las que se pueden agrupar los elementos más usados en los cómics para crear identidad geográfica: las peculiaridades de los personajes, el mundo circundante y las memorias o los recuerdos.

19 Vargas, H. El negro Fontanarrosa. Argentina, Homo Sapiens Ediciones, 2014, p. 149.

${ }^{20}$ Ibid., p. 149.

${ }^{21}$ Ibid., p. 151.

${ }^{22}$ Ibid., pp. 4-5. 
Para empezar a crear la identidad geográfica de un personaje, se utilizan elementos básicos como nombre, apellido y profesión u oficio. También se agregan características étnicas y estereotipos de la complexión física que corresponden a una etnia en particular: los nativos de Maui son obesos; los italianos son guapos; los ingleses tienen los dientes feos. A estos rasgos se agrega la ropa y las representaciones de la moral e ideología de la cultura que acoge a los personajes. Los personajes también pueden mostrar poder político y ser poderosos e intimidantes ante otros personajes. Muestran un comportamiento sexual o de género que denota su origen, y, desde luego, a través de la comunicación, pueden mostrar algunos rasgos de la cultura en la cual se han desarrollado. Por las imágenes o palabras, podemos conocer la clase social a la que pertenecen y las prácticas familiares o tradiciones comunitarias, culturales o religiosas que practican. Las relaciones interpersonales de los personajes también aportan información sobre su origen o cercanía por un lugar.

El mundo que circunda al personaje tiene, desde luego, a decisión del creador, los elementos más naturales y fáciles para denotar la ubicación geográfica de la historieta. Estos elementos incluyen: el nombre de la locación, área, barrio, ciudad, o país y los paisajes. Los itinerarios de viaje del personaje, y el ambiente socioeconómico del lugar también otorgan información. Las características generales de la población apoyan en la manera en cómo se reconocerá el lugar. El nivel de civilidad de los personajes que circundan al protagonista —en la memoria colectiva - indica, por ejemplo, si la historia ocurre en otra época. Los avances tecnológicos también dan este tipo de información: televisores, computadoras y celulares nos sitúan inmediatamente en un tiempo determinado.

En la locación de una historia también se considera el tiempo en el que esta ocurre. Un ejemplo reciente: la Dublín irlandesa de Dublinés no es la misma que la del cuaderno de viaje La ruta Joyce, ambas obras de Alfonso Zapico. Muchos cómics sobre conflictos bélicos necesitan de información sobre la época para completar la visión del lugar donde ocurren las historias. 2324

Algunos medios de transporte - barcos, canoas, aviones y carros- muestran la manera en la que los protagonistas viajan de un lugar a otro y son referencias de la época en que esto ocurre. El clima, la flora y la fauna también pueden retratar un lugar con precisión. Los eventos históricos, políticos y sociales, así como las tradiciones populares, son referentes determinantes de la ubicación de un personaje.

Las representaciones visuales en los cómics suelen incluir referencias a mitos y leyendas de regiones particulares. Se incluyen también estereotipos climáticos: un Londres nublado, un Seattle con lluvia, o una Nueva York en medio de una fuerte ventisca. En este apartado de memorias y recuerdos se incluyen los flashbacks o escenas referentes a las vivencias pasadas de los personajes durante su infancia o juventud y el lugar donde ocurrieron. También se agrupan en esta categoría mapas o descripciones con direcciones precisas.

${ }^{23}$ Zapico, A. Dublinés. Bilbao, Astiberri, 2011.

${ }^{24}$ Zapico, A. La ruta Joyce, Bilbao. Astiberri, 2011. 


\section{Inodoro Pereyra: la Pampa argentina en la distancia}

Vargas considera que la obra maestra de Fontanarrosa es la serie de Inodoro Pereyra (19722007), «que ha sido también catalogada como un producto inexportable debido a las múltiples menciones de asuntos locales y a la representación específica de los habitantes de la Pampa argentina». ${ }^{25} \mathrm{El}$ entusiasta del cómic se siente irremediablemente atraído por esta serie, sin importar los retos que acarrea la lectura de sus particularidades sobre la localidad. Plagada de viñetas con planos panorámicos de la región, Inodoro Pereyra cuenta la historia y aventuras - a veces desventuras - , de un hombre nacido en la provincia argentina, un ser iletrado, muy guerrero y defensor de lo suyo, un «héroe de carisma terruñal». ${ }^{26}$

Inodoro vive en una casa de adobe muy humilde, con un solo árbol a la vista, continuamente se le ve caminando en la distancia. Fontanarrosa gusta de retratar desde lejos su terruño. Inodoro es pareja de Eulogia Tapia y tiene por acompañante — en la forma de un perro- a Mendieta, que funge como su compinche de aventuras. Inodoro siempre va descalzo y despeinado, con una vincha en la cabeza.

Fontanarrosa utiliza numerosos paisajes para situar la historia en la provincia rural de Argentina. En las viñetas podemos ver los campos, los ranchos y las casas. Estos son mencionados también de forma verbal. El lector percibe que el creador tiene lazos profundos con este terruño. «Fontanarrosa nunca vivió en la Pampa, pero sí tuvo una nana que venía de la provincia, de ancestros indígenas y que se apellidaba Pereyra». ${ }^{27}$ Además de los paisajes que lo circundan, Inodoro tiene algunas características físicas, culturales y de comportamiento, que indican su origen humilde. Su discurso y su modo de hablar son los de un hombre que no ha tenido educación formal. Fontanarrosa escribe los diálogos de Inodoro con otra palabra: «yamado» por «llamado», «yastoy» por «ya estoy», «dispacito» por «despacito», y «dinidad» por «dignidad», entre muchas más. El efecto de lectura de estas palabras denota directamente características del habla y de la personalidad de Inodoro: de clase baja, locación rural y de poca o ninguna formación educativa formal. El lector que no pertenece a la localidad también es sorprendido por vocablos regionales cuyos significados son oscuros: clinas, charango, cascanudos y cuises, entre otras.

Fontanarrosa retoma referentes gauchescos de fuentes literarias e historieta gauchesca, presentando «en toda su complejidad las distintas vinculaciones sociales, intercambios culturales y dependencias económicas recíprocas existentes entre los grupos blancos e indios», ${ }^{28}$ creando un panorama que da pie a la sátira, a la crítica política y a la visión personal sobre un lugar específico.

25 Vargas, H. Op. cit., pp. 4-5.

26 Fontanarrosa, R. Inodoro Pereyra 5. Argentina, Grupo Editorial Planeta, 2013, p. 5.

27 VARgas, H. Op cit., pp. 33-34.

${ }^{28}$ Landa, C.G. y Spota, J.C. «Trazos fronterizos. Representación de la frontera sur con el indio durante el siglo XIX en la historieta argentina. Algunas reflexiones desde la antropología y la arqueología histórica», en Gazeta de Antropología, 27 (2), artículo 35 (2011), p. 1. 
Sin embargo, ante la dificultad de entender ciertos vocablos, el lector actual puede inferir que, de encontrarse frente a frente con Inodoro en un universo alterno, no entendería lo que dice y reacciona ignorando ciertos términos, pero comprendiendo otros. Aunque el español nos identifica como latinoamericanos, al mismo tiempo genera cierto distanciamiento en virtud de la cultura y del lenguaje local de cada región.

Fontanarrosa decide tener personajes invitados en Inodoro Pereyra, personajes que provienen de otras localidades, que pertenecen a otras culturas o a otros grupos étnicos, y los presenta utilizando algunos estereotipos o nombres específicos, es decir, utilizando el gentilicio para introducirlos en la historia. Así, en la serie pueden observarse habitantes de México, Estados Unidos, Rusia, Japón o Medio Oriente, y pobladores nativos norteamericanos y sudamericanos. Los mexicanos son retratados con grandes sombreros y largos rifles montando a caballo, grandes cartucheras les cruzan el pecho y anuncian que participaron en la Revolución y vienen desde Ciudad Juárez. ${ }^{29}$

Los estadounidenses aparecen como turistas ante Inodoro, con cámaras, lentes oscuros y gorras de béisbol, le toman fotos y se despiden con alegres «Bai», «Bai», «Bai». ${ }^{30}$ Un personaje japonés aparece con la cabeza rapada, grandes dientes, ojos rasgados y saluda con un «arigató, arigató» («gracias, gracias») en la viñeta en la que se presenta ante Inodoro haciendo una inclinación con el cuerpo de casi noventa grados. ${ }^{31}$ Cada uno de los personajes de otras regiones se representa con sus rasgos físicos específicos, utilizando en su mayoría estereotipos de uso cotidiano para completar sus caricaturas. Todos estos personajes aparecen en la historieta y muestran la versatilidad que Fontanarrosa tenía para retratar personas y conferirles una identidad geográfica.

Además de estos gentilicios, Fontanarrosa, también retrató personajes icónicos en Inodoro Pereyra, entre ellos y como transportados en una máquina del tiempo a Don Quijote y a un grupo de conquistadores españoles, con sus yelmos y sus mosquetes. También encontramos figuras de la cultura estadounidense ataviados como se representan comúnmente. Entre ellos podemos nombrar a Papá Noel, a E.T. a quien Mendieta confunde con un turista brasileño, a Annie, la huerfanita, a Batman, de quien Eulogia opina: «i[n]unca he visto un murciélago tan güen mozo!», ${ }^{32}$ a Superman y a Hulk que «Es verde, sí... Pero verde esperanza». ${ }^{33} \mathrm{~A}$ través de Inodoro, Fontanarrosa habla de lo que conoce, de un mundo circundante, de lo que le parece interesante de la cultura provincial. Inodoro representa, pero a la vez ejemplifica las posibilidades de satirizar su cultura. Inodoro es una serie compleja, su protagonista es alguien a quien aprendemos a querer, a quien le deseamos buena fortuna y de quien nos avergonzamos de vez en cuando, reaccionamos con pena ante sus desdichas, pero comprendemos que su esencia es esa, y estamos de acuerdo.

\footnotetext{
${ }^{29}$ Fontanarrosa, R. 20 años con Inodoro Pereyra. Argentina, Ediciones la Flor, 1998.

30 Ibid., p. 42.

${ }^{31}$ Ibid., p. 412.

32 Ibid., p. 524.

33 Ibid., p. 259.
} 


\section{Boogie el aceitoso: la violencia que nunca duerme}

Boogie el aceitoso (1972-1995), a diferencia de Inodoro Pereyra, es un cómic que ha sido exitoso en muchos países, como Italia, Colombia, Brasil y México. Parodiando las películas de Harry el sucio, Boogie es un mercenario que además de asesinar y golpear por dinero, hace cualquier cosa que le pidan, como cuidar niños y modelar desnudo para algunos pintores. ${ }^{34}$ La serie se publicó semanalmente de 1972 a 1995.35

Boogie vive en Nueva York, y esto es un hecho que se percibe desde los primeros ejemplares de la serie. El nombre de Nueva York como el lugar en donde se desarrolla la vida de Boogie es mencionado en pocas ocasiones en las más de quinientas tiras, pero no es solo el nombre lo que persuade al lector que presencia el Nueva York de finales del siglo xx. Fontanarrosa presenta una gran cantidad de elementos para señalar la identidad geográfica de Boogie el aceitoso. Por aquellos años, Nueva York representaba el espíritu cosmopolita y citadino, por ser el centro mundial del comercio (WTC), una ciudad atractiva y a la vez peligrosa, donde convergían muchas y variadas culturas.

Los recuerdos de los personajes son muy recurrentes en Boogie, debido a que, de vez en cuando, estos se sientan a platicar y se presentan flashbacks que describen visual y verbalmente diferentes recuerdos o memorias vividas por Boogie y por sus acompañantes. Fontanarrosa nombra algunos lugares famosos para darle a la serie ese ambiente neoyorkino que está en la memoria colectiva de los lectores, lugares como el Bronx, Brooklyn, la Calle 42 y el Central Park son algunos ejemplos.

Los personajes se hacen neoyorkinos cuando Fontanarrosa los nombra; Boogie es el primero, pero aparecen en la serie decenas de nombres anglosajones o judíos entre los cuales encontramos algunos tan complejos como: Anthony Brodsky, Betty Whithacker, Peter Warren Trent, y Rosalie Marie Millerd y algunos otros nombres propios comunes en la cultura estadounidense: Sue, Quincy y Harvey.

Los personajes hablan con palabras en inglés, pero a través de una castellanización fonética en los diálogos: «Gud bai» por «goodbye», «Jelou» por «hello», «Shet» por «shit»; como una parodia de la pronunciación norteamericana. Además de estas expresiones, encontramos en algunos ejemplares de la serie fragmentos de canciones en inglés. En múltiples viñetas también existen palabras en inglés expresadas por los personajes como: «Oh, God!» $\mathrm{y}$ «Ouch». Entre los elementos del mundo circundante que crean la identidad geográfica de Boogie, aparecen los nombres de lugares particulares de la ciudad de Nueva York: Queensborough, Newark Street y Long Island; $\mathrm{y}$ los letreros y anuncios publicitarios que señalan los lugares por los que camina Boogie: «Subway New York», «OPEN COME IN» y «POLICE NY». Las onomatopeyas de acciones, principalmente golpes o actos violentos, son recurrentes y se expresan en inglés, de manera muy similar a las de los cómics norteamericanos: «bang», «crash», «clik» $y$ «riiing», son algunas de ellas.

${ }_{34}$ Vargas, H. Op. cit., p. 41.

35 Ibid., p. 41. 
En Boogie, Fontanarrosa también representa personajes de otras culturas, nacionalidades y hasta «razas». Entre los personajes que se topan con Boogie, generalmente como antagonistas, Fontanarrosa incluye gente originaria de Italia, Japón, Vietnam, China, Norteamérica, Perú, Sudamérica, Palestina y Puerto Rico, además de representar a latinos, chicanos, afroamericanos, talibanes, árabes y miembros del Ku Klux Klan. Todo este desfile de nacionalidades retrata fielmente la idea de que la ciudad de Nueva York es un melting pot, un crisol, una ciudad cosmopolita donde convergen diversas culturas y se amalgaman mientras se adaptan a la ciudad y a la sociedad estadounidense.

Boogie no tiene ningún empacho en nombrar e insultar a los que, al parecer, le son ajenos. Cuando Fontanarrosa representa afroamericanos, algunas veces aparecen con piel oscura, otras con una leve sombra, siempre con los labios gruesos, la nariz ancha, y el pelo rizado. Ellos llevan la peor parte de la actitud de Boogie quien les dice: «Escucha sucio negro racista ${ }^{36}$ "Quítate de mí vista, mandril». ${ }^{37} \mathrm{~A}$ los japoneses los retrata con dientes grandes, pelones o rapados, inteligentes y muy buenos negociantes. La visión de Boogie es una representación de la del norteamericano racista y clasista y su retrato es una crítica social que hace su creador sobre sus características.

En Boogie, la ciudad de Nueva York está representada en imágenes visuales de edificios angostos, calles oscuras, señales de tránsito, azoteas vacías, paisajes con parques públicos, avenidas, restaurantes y bares. Además de interiores de departamentos minúsculos pero acogedores, muchas veces en viñetas pequeñas muy detalladas que acompañan como descriptores a la información temática de cada historia. Nueva York, durante las últimas décadas del siglo $\mathrm{xx}$, se convirtió en una de las ciudades más importantes del mundo y fue para muchos una ilusión, un sueño hecho realidad. Por lo tanto, es comprensible la actitud del lector ávido por saber, conocer y ver más de tal locación. Con respecto a Boogie, es un protagonista malvado, coherente con sus acciones de mercenario y quien pareciera que disfruta con el odio que podamos otorgarle, sin embargo, su representatividad como instrumento de crítica social, su protagonismo y su coherencia lo volvieron un icono de la narrativa gráfica del siglo xx.

\section{Los clásicos según Fontanarrosa: la vuelta al mundo en ochenta páginas}

Las historias contenidas en el volumen Los clásicos según Fontanarrosa fueron publicadas por primera vez a mediados de los años setenta en diferentes revistas, para finalmente aparecer en un volumen de Ediciones de La Flor en 1980. Cada historieta es una parodia de una obra literaria clásica. El volumen incluye La isla del tesoro, La cabaña del tío Tom, Moby Dick, Hansel y Gretel y El flautista de Hamelin, entre muchas otras.

En esta colección de historietas, la preocupación de situar la narración en un tiempo pasado resalta los elementos de identidad geográfica más que en ninguna otra serie de Fonta-

\footnotetext{
36 Fontanarrosa, R. Todo Boogie el aceitoso. Argentina, Ediciones la Flor, 1999, p. 63.

37 Ibid., p. 272.
} 
narrosa. Cada historia utiliza varias viñetas y muchos fondos para representar la atmósfera original de cada texto, la que se espera al leer el título de la obra parodiada y recordar de lo que trata la historia. Mares, barcos, bosques, desiertos, campos de batalla, castillos medievales, selva tropical y sembradíos de algodón acompañan a los personajes de estos relatos.

Las primeras dos historias, en orden de aparición, son La Ilíada y La Odisea, narrativas gráficas en las que Fontanarrosa logra hacer muy claro que la historia tiene lugar en la Antigua Grecia. El primer personaje en aparecer en la primera viñeta de La Ilíada es Homero, quien, sentado sobre una piedra, toca un instrumento musical y canta una historia. En el segundo panel, otro personaje lo nombra y describe su ceguera y su profesión de bardo. ${ }^{38}$ Hay una mezcla de descripciones verbales y visuales de los demás personajes, Aganmelón (representando a Agamenón) porta un casco, una armadura y armas similares a las que la memoria colectiva acepta como vestimenta militar de la cultura grecorromana. Fontanarrosa también plasma un Partenón con un letrero donde se lee: OLIMPO en la parte alta de su fachada. En la historieta se mencionan los nombres de los personajes de la historia original para enfatizar el origen de esta parodia: Helena, Minerva, Héctor, Ulises, Patroclo, Aquiles, Paris y Marte. En algún momento también se señala a Troya como un lugar en la historia. Estos y otros elementos también aparecen en la parodia de La Odisea. La primera palabra que aparece en el cómic es el nombre de Ulises, gritado por Penélope y entonces se narra un pequeño resumen de sus experiencias de viaje. Fontanarrosa representa seres mitológicos de la historia que está parodiando: sirenas, cerdos parlantes y un cíclope para dar al lector la impresión de un viaje fantástico. ${ }^{39}$

En la historia de Ali Baba y los 40 ladrones, el fondo está compuesto por rocas y un paisaje desértico que simula arena por doquier. Los personajes tienen una indumentaria arabesca, tienen la piel y el cabello oscuros, usan turbantes, sombreros o se cubren el rostro con telas, sus narices son de gran tamaño y sus miradas y actitudes son temerarias. Al final de esta parodia, Fontanarrosa menciona el conflicto político entre Israel y Palestina. ${ }^{40}$ En la parodia de Otelo de William Shakespeare, Otelo muestra facciones toscas y piel morena. Los paisajes retratan Venecia, sus canales y las góndolas en las que transitan los personajes. Los diálogos están escritos en verso y los personajes adoptan poses muy dramáticas como si representaran una obra teatral en lugar de ser personajes de una historieta. Con igual fuerza, la identidad geográfica de Ivanhoe está denotada por una justa medieval entre dos caballeros, las armaduras de estos, sus lanzas, los vestidos de las damas de la corte, los ropajes del clero y los cortes de cabello de los personajes. ${ }^{41} \mathrm{La}$ arquitectura de los castillos también recuerda a construcciones medievales, así como los muebles y decoraciones del trono. En la historieta paródica de Robinson Crusoe, todas las viñetas incluyen flora y fauna tropical con muchos planos panorámicos de la isla, el mar que la rodea y la balsa donde navegan Robinson y su acompañante,

\footnotetext{
38 Fontanarrosa, R. Los clásicos según Fontanarrosa. Argentina, Ediciones la Flor, 1980, p. 5.

39 Ibid., pp.13-20.

40 Ibid., pp.21-29.

${ }^{41}$ Ibid., pp.30-35.
} 
quien no se llama Viernes sino Domingo, y que es «un pigmeo caníbal» ${ }^{42}$ representado con facciones africanas, un hueso en la cabeza y varios orificios de aretes gigantes en las orejas.

Vincent Debiais cree que «cuando los personajes se presentan a sí mismos en un cómic, a veces ellos introducen su identidad geográfica», ${ }^{43}$ a veces esta se revela paralelamente a la historia mientras el personaje vive su relato. Fontanarrosa es experto en ambos formatos. Nos presenta - a través de Inodoro y de Boogie— la información que explica su identidad, aunque inicialmente, para conocimiento de los demás personajes, así consecuentemente del lector. El personaje, a través de su creador, tiene conciencia de su propia identidad y tiene a su disposición toda la información necesaria para transmitirla. Es entonces que el lector reconoce la geografía de ese lugar a través de una asociación cultural o un recuerdo o bien se adentra con confianza por primera vez en ella: crédulo. El creador está consciente de que necesita apelar a este reconocimiento o confianza para que su historia tenga sentido. ${ }^{44}$ Existe un acuerdo tácito entre el artista y sus lectores, que aceptan con gusto, las locaciones de Inodoro y Boogie para el disfrute de dos diferentes narrativas.

\section{Conclusión}

Fontanarrosa retrata las profesiones y actividades de sus personajes que los identifican propios de algún lugar. También sus apelativos ayudan a situarlos en un contexto geográfico. La historia que se cuenta es un factor que tiene coherencia con los anteriores elementos. En los textos revisados, las historias ocurren en diferentes lugares y momentos en el tiempo, pero en ellos, los elementos necesarios para entender donde ocurre la historia son constantes y minuciosos. Al parecer, el lector de Fontanarrosa, sabe que el creador «promete» una representación reconocible de lugares y que se apega a ella dando cada vez más información, siempre relevante y siempre coherente.

Fontanarrosa nos adentra en el Nueva York del mercenario Boogie y, en tan solo una viñeta, nos transporta a Vietnam, a un campo de batalla a través del relato, para llevarnos dos viñetas después a un plácido Central Park con todo y su lago. De igual forma, Fontanarrosa nos lleva a un Olimpo de La Ilíada en donde Homero canta sus historias y a una Ítaca de $L a$ Odisea en dónde Ulises se reencuentra con Penélope. Pero de vuelta a casa, en algún lugar de las pampas argentinas, Inodoro espera sentado fuera de su casa platicando con Mendieta sobre las cosas de la vida que no le son gratas.

Mientras muchos seres humanos «ya no transitamos por los parajes cotidianos que conducen al hombre a crear su identidad en el lugar», ${ }^{45}$ el cómic sí requiere y reproduce esta

\footnotetext{
42 Ibid., p. 68.

43 Debiais, V. «Transmitir la identidad. Difusión y promoción de la identidad en las inscripciones publicitarias de la Navarra medieval», en Actas del VI Congreso de Historia de Navarra, (2006), pp. 66-80, p. 3.

44 Ibid., p. 4.

45 Pérez Arriaga, R. Op. cit., p. 41.
} 
identidad, haciéndolo un género para el disfrute y placer del que anhela un sentido de pertenencia, aunque sea solo por el tiempo en que lee y recrea ese mundo imaginario. La selección de elementos para crear la identidad geográfica de los personajes tiene relación con el impacto que produce la historia en el lector y, a gran escala, en el posible público general. Hay quien pueda preguntarse si el Nueva York tan enigmático y magnético de Boogie es parte de su éxito, o si la territorialidad de Inodoro y sus modos tan locales le impidieron ser leído en otros países de habla hispana durante sus primeros años. Las parodias de Los clásicos, por su parte, quedarán como una muestra, como un catálogo de todos los elementos necesarios para persuadir a los lectores de viajar por el mundo a través del tiempo y el espacio en una historieta. De Ítaca a Inglaterra, de una isla desierta a España, a Londres, al sur de los Estados Unidos, convirtiendo así al cómic de Fontanarrosa no solo en un mapa del tiempo y del espacio gráfico de una narración, sino en un mapa del tesoro, mostrando, así, que el noveno arte es un verdadero mapa del tesoro en la vida del hombre. 


\section{Bibliografía}

Ausente, D. «La memoria gráfica y las sombras del pasado», en García, S. (coord.). Supercómic. Mutaciones de la novela gráfica contemporánea. Madrid, Errata naturae, 2013, p.109.

Ayala, P. El cómic y sus razones. México, Universidad de Colima, 2016.

Debiais, V. «Transmitir la identidad. Difusión y promoción de la identidad en las inscripciones publicitarias de la Navarra medieval», en Actas del VI Congreso de Historia de Navarra, (2006), pp. 66-80.

Dittmer, J. «Comic book visualities: a methodological manifesto on geography, montage and narration", en Transactions of the Institute of British Geographers New Series, vol. 35, n. $^{\circ}$ 2, (2010), pp. 222-236.

Dunnett, O. «Identity and geopolitics in Hergé’s Adventures of Tintin», en Social छ Cultural Geography, vol. 10, n. ${ }^{\circ}$ 5, (2009), pp. 583-598.

Emmerson, P. «Doing comic geographies», en Cultural Geographies, vol. 23, n. * 4, (2016), pp. 721-725.

Fontanarrosa, R. 20 años con Inodoro Pereyra. Argentina, Ediciones la Flor, 1998.

- Inodoro Pereyra 5. Argentina, Grupo Editorial Planeta, 2013.

- Los clásicos según Fontanarrosa. Argentina, Ediciones la Flor, 1980.

- Todo Boogie el aceitoso. Argentina, Ediciones la Flor, 1999.

Landa, C.G. y Spota, J.C. «Trazos fronterizos. Representación de la frontera sur con el indio durante el siglo XIX en la historieta argentina. Algunas reflexiones desde la antropología y la arqueología histórica», en Gazeta de Antropología, 27 (2), artículo 35, (2011), pp. 1-12.

Hernando, A. «Retórica iconográfica e imaginación geográfica: los frontispicios de los atlas como proclamaciones ideológicas», en Boletin de la A.G.E., n.o 51, (2009), pp. 353369.

Martín-Barbero, J. «Jóvenes: comunicación e identidad», en Revista Pensar Iberoamérica (0), OEI, (2002), pp. 1-15.

Pérez Arriaga, R. «La ciudad, lugar de identidad geográfica y cultural», en Fermentum. Revista Venezolana de Sociología y Antropología. vol. 19, n. o 54, (2009), pp. 35-47. 
Rodríguez Pequeño, M. «Crónica urbana e identidad geográfica en la narrativa de Miguel Delibes y Francisco Umbral», en Actas XLV (AEOE, s.f.), pp. 325-332.

TAYLOR, S. Narratives of Identity and Place. London, Routledge, 2010.

VArgas, H. El negro Fontanarrosa. Rosario, Homo Sapiens Ediciones, 2014.

Zapico, A. Dublinés. Bilbao, Astiberri, 2011.

Zapico, A. La ruta Joyce. Bilbao, Astiberri, 2011. 